\title{
Synthesis and Electrochemical Characterization of Silica-Manganese Oxide with a Core-shell Structure and Various Oxidation States
}

\author{
Seong-Hyeon Ryu, Seung-Gi Hwang, Su-Ryeon Yun, Kwon-Koo Cho, ${ }^{\dagger}$ Ki-Won Kim, ${ }^{\dagger}$ and Kwang-Sun Ryu* \\ Department of Chemistry, University of Ulsan, Ulsan 680-749, Korea. *E-mail: ryuks@ulsan.ac.kr \\ ${ }^{\dagger} i$-Cube Center, ITRC for Energy Storage and Conversion, Gyeongsang National University, Jinju, \\ Gyeongsangnamdo 660-701, Korea \\ Received April 2, 2011, Accepted June 28, 2011
}

\begin{abstract}
Silica-manganese oxides with a core-shell structure were synthesized via precipitation of manganese oxides on the $\mathrm{SiO}_{2}$ core while varying the concentration of a precipitation agent. Elemental analysis, crystalline property investigation, and morphology observations using low- and high-resolution electron microscopes were applied to the synthesized silica-manganese oxides with the core-shell structure. As the concentration of the precipitating agent increased, the manganese oxide shells around the $\mathrm{SiO}_{2}$ core sequentially appeared as $\mathrm{Mn}_{3} \mathrm{O}_{4}$ particles, $\mathrm{Mn}_{2} \mathrm{O}_{3}+\mathrm{Mn}_{3} \mathrm{O}_{4}$ thin layers, and $\alpha-\mathrm{MnO}_{2}$ urchin-like phases. The prepared samples were assembled as electrodes in a supercapacitor with $0.1 \mathrm{M} \mathrm{Na}_{2} \mathrm{SO}_{4}$ electrolyte, and their electrochemical properties were examined using cyclic voltammetry and charge-discharge cycling. The maximum specific capacitance obtained was $197 \mathrm{~F} \mathrm{~g}^{-1}$ for the $\mathrm{SiO}_{2}-\mathrm{MnO}_{2}$ electrode due to the higher electronic conductivity of the $\mathrm{MnO}_{2}$ shell compared to those of the $\mathrm{Mn}_{2} \mathrm{O}_{3}$ and $\mathrm{Mn}_{3} \mathrm{O}_{4}$ phases.
\end{abstract}

Key Words : Silica-manganese oxide, Core-shell structure, Supercapacitor, Electrode, Oxidation state

\section{Introduction}

Supercapacitors (ultra capacitors or electrochemical capacitors) are used as back-up power supplies for real-time clock electronics and are also widely used in industrial applications. Supercapacitors are charge (or energy) storage devices which can withstand higher powers than batteries and that can deliver higher energies than conventional electrostatic or electrolytic capacitors. Supercapacitors can be used as auxiliary energy devices along with a primary power enhancement in short-pulse applications. Electrochemical supercapacitors are classified based upon the mechanism of charge storage. One example is the electrical double layer capacitor, in which the capacitance arises from charge separation at the electrode/electrolyte interface. Another example is a pseudocapacitor (or redoxcapacitor), in which capacitance arises from faradaic reactions which, for a variety of different reasons, exhibit capacitive behavior. ${ }^{1-4}$

The most widely used materials for supercapacitors include carbon, conducting polymers, and transition metal oxides. In electrical double layer capacitor systems, carbon in the form of active carbon or carbon nanotubes is generally used as the electrode material. In pseudo- or redox supercapacitor systems, transition metal oxides (ruthenium oxide, nickel oxide, and manganese oxide) and conducting polymers (polyaniline or polypyrrole) are commonly used as the electrode materials. ${ }^{3}$ Among the different transition metal oxides, amorphous hydrous $\mathrm{RuO}_{2}$ has a high specific capacitance $\left(\sim 760 \mathrm{~F} \mathrm{~g}^{-1}\right)$ due to solid-state pseudo-faradaic reactions. ${ }^{5,6}$ However, its high cost, low porosity, and rapid decrease in power density at high charge-discharge rates are among the disadvantages of using $\mathrm{RuO}_{2} \cdot x \mathrm{H}_{2} \mathrm{O}$ in practical supercapacitors. ${ }^{7}$ Therefore, manganese oxides have received much attention and interest due to their low cost, natural abundance, and environmentally benign properties.

Manganese oxide can be synthesized via thermal decomposition, co-precipitation, sol-gel processes, electrochemical deposition, solution-based chemical routes, and solid-state reactions. ${ }^{8-16}$ Changes in the synthesis parameters such as current density, temperature, reactant concentration, and $\mathrm{pH}$ result in different physical, chemical, and electrochemical properties of manganese oxide. The synthesis conditions determine the intrinsic properties of the manganese oxide produced. Previously reported manganese oxides demonstrated specific capacitances as high as $600 \mathrm{~F} \mathrm{~g}^{-1}$ for thin films and 150-300 $\mathrm{F} \mathrm{g}^{-1}$ for powder-based electrodes within a potential window of $0.9-1.2 \mathrm{~V}$ in aqueous electrolytes containing $\mathrm{KCl}, \mathrm{K}_{2} \mathrm{SO}_{4}, \mathrm{NaCl}$, or $\mathrm{Na}_{2} \mathrm{SO}_{4} \cdot{ }^{10-20}$

On the other hand, a surface nanoparticle coating has been used with various materials to form core-shell morphologies, resulting in the formation of new composite materials that can be used in the areas of electrochemistry, magnetics, mechanics, thermal conduction, electro-optics, electronics, photonics, and catalysis. ${ }^{21-28}$ Silica coated with other materials is a classic combination which is widely used in many fields. In fact, silica has many merits when used in core-shell structures. First, silica can be easily produced in a controlled manner with a spherical morphology on the nano to micron scale. When silica spheres are coated with electro-active material, a spherical core-shell electro-active material will be obtained. The size of the electro-active material can be controlled by the sizes of the silica cores. Secondly, the nonagglomerated particles, narrow size distribution, and spherical shape offer many sites for the reduction reactions of the 
electro-active material. $^{29}$

In this study, we synthesized silica and silica-manganese oxides with core-shell structures via the stöber and precipitation methods. The phases of the manganese oxides produced on the shell were controlled through the use of chelating and precipitation agents, which changed the oxidation states of the manganese species. The resultant silica-manganese oxides with different oxidation states were compared in terms of their physical and electrochemical properties for use as the electrode material of supercapacitors.

\section{Experimental}

The uniform silica spheres were synthesized using the stöber method. The silica nanoparticles were prepared using ammonia as a catalyst in order to form spherical particles. A $100 \mathrm{~mL}$ solution of $0.2 \mathrm{M}$ tetraethylortho silicate (Aldrich) and ethanol (Daejung) was stirred for $1 \mathrm{~h}$. Another $100 \mathrm{ml}$ solution consisting of $0.6 \mathrm{M} \mathrm{NH}{ }_{4} \mathrm{OH}$ (Daejung), $17 \mathrm{M}$ deionized water, and ethanol was stirred for $1 \mathrm{~h}$. The two solutions were mixed into one vessel and constantly stirred to obtain a colloid state. The silica colloid was centrifuged and washed with deionized water and ethanol to yield a $\mathrm{Si}(\mathrm{OH})_{2}$ gel. The gel was then dried at $70{ }^{\circ} \mathrm{C}$ for $10 \mathrm{~h}$ to obtain silica nanoparticles.

The silica nanoparticles ( $1 \mathrm{~g}$ ) were dispersed in deionized water via ultrasonication for $2 \mathrm{~h}$. A $0.044 \mathrm{M} \mathrm{MnSO} \cdot \mathrm{H}_{2} \mathrm{O}$ (Samchun Chem.) solution was dissolved in deionized water and added dropwise to the silica solution under stirring. A mixed aqueous solution of $0.088 \mathrm{M} \mathrm{NH}_{4} \mathrm{OH}$ and $\mathrm{NaOH}$ as a precipitation agent (varied among $0,0.022$, and $0.088 \mathrm{M}$ ) was also added dropwise to the silica solution under stirring. The black precipitate was washed with deionized water and dried at $70{ }^{\circ} \mathrm{C}$ for $10 \mathrm{~h}$. The dried powder as a silicamanganese oxide precursor was heated at a rate of $1.5^{\circ} \mathrm{C}$ $\min ^{-1}$ to $300{ }^{\circ} \mathrm{C}$, maintained for $3 \mathrm{~h}$, and cooled naturally to room temperature.

The morphologies of the silica-manganese oxide powders obtained with core-shell structures were evaluated using a field emission scanning electron microscope (FE-SEM, JSM-6500F, Jeol) and a field emission transmission electron microscope (FE-TEM, JEM 2100F, Jeol). The weight ratios of the metal elements were evaluated using inductively coupled plasma emission spectroscopy (ICP, Iris Duo, Thermo Electron). The X-ray diffraction (XRD) patterns were measured using a X-ray diffractometer (Ultra-X, Rigaku, $\mathrm{CuK}_{\alpha}$ radiation) at a step scan of $0.02^{\circ}$ to identify the crystalline phases of the silica-manganese oxides powders with core-shell structures. Fourier transform infrared (FTIR) spectra were also recorded using a FT-IR spectrometer (Varian 2000) in the wavenumber range of 400 to 4,000 $\mathrm{cm}^{-1}$. For the FT-IR test, the solid samples were diluted in $\mathrm{KBr}$ pellets.

The supercapacitor electrode was prepared by mixing and drying a mixture of the silica-manganese oxide with a coreshell structure (75 wt \%) as an active material, carbon black
(20 wt \%, Super P, Timcal Graphite \& Carbon) as a conductive agent, poly(tetrafluoroethylene) ( $5 \mathrm{wt} \%$, Aldrich) as a polymer binder, and $6 \mathrm{~mL}$ of ethanol in deionized water as a solvent. The dried mixture was converted to a rubber-like paste by pressing with isopropyl alcohol. The electrode, which was used as both the cathode and anode, was pressed onto a nickel-mesh current collector and surrounded with a separator. The supercapacitor cell was assembled by superimposing the cathode/separator/anode sheets with a $0.1 \mathrm{M}$ $\mathrm{Na}_{2} \mathrm{SO}_{4}$ electrolyte and vacuum sealing within an aluminum pouch. For the supercapacitor cell, cyclic voltammetry (CV, WBCS3000, WonA Tech) was performed within the range of -0.2 to $1.0 \mathrm{~V}(v s$. SCE) at a scan rate of $5 \mathrm{mV} \mathrm{sec}$. Galvanostatic charge-discharge cycling in the potential range of $-0.2 \mathrm{~V}$ to $1.0 \mathrm{~V}$ was also performed at constant current densities of 0.1 and $0.2 \mathrm{~A} \mathrm{~g}^{-1}$.

\section{Results and Discussion}

The precipitated silica nanoparticles have a three-dimensional network structure and contain silanol $(\mathrm{Si}-\mathrm{OH})$ groups on the surface. Silanol and siloxane groups are conventionally created on the silica surface, leading to the hydrophilic nature of the particles. Silica surfaces are typically classified into three silanol types: free or isolated silanols, hydrogen-bonded or vicinal silanols, and geminal silanols. ${ }^{30}$ The manganese oxides can be synthesized through chelation and precipitation due to the manganese cations arranged around the silica nanoparticles. At this stage, the oxidation state of manganese oxide can be adjusted by varying conditions such as the alcohol, electrochemistry, and temperature. ${ }^{7,31,32}$ In the present work, the low reaction temperature slowly releases free $\mathrm{Mn}^{2+}$ cations from the stable precursor. These $\mathrm{Mn}^{2+}$ cations then form amine complexes of $\mathrm{Mn}\left(\mathrm{NH}_{3}\right)_{n}{ }^{2+}(n=1-4)$ with $\mathrm{NH}_{3}(\mathrm{aq})$ in a moderately basic medium (e.g., $\mathrm{pH}=8$ ). Due to the formation of amine complexes, the solution does not contain colloidal manganese hydroxide in the deposition solution. The chelation reaction can be expressed as follows.

$$
\begin{gathered}
\mathrm{NH}_{4} \mathrm{OH} \rightleftarrows \mathrm{NH}_{3}+\mathrm{H}_{2} \mathrm{O} \\
\mathrm{Mn}^{2+}+n \mathrm{NH}_{3} \rightleftarrows \mathrm{Mn}\left(\mathrm{NH}_{3}\right)_{n}{ }^{2+}
\end{gathered}
$$

In this work, the oxidation state of the manganese oxides is controlled by the concentration of the $\mathrm{NaOH}$ precipitation agent. The precipitation reactions are as follows.

$$
\begin{aligned}
6 \mathrm{Mn}\left(\mathrm{NH}_{3}\right)_{4}{ }^{2+} & \rightleftarrows 6 \mathrm{Mn}^{2+}+24 \mathrm{NH}_{3}+24 \mathrm{H}_{2} \mathrm{O}+8 \mathrm{OH}^{-} \\
& \rightleftarrows 2 \mathrm{Mn}_{3}(\mathrm{OH})_{4}+24 \mathrm{NH}_{4} \mathrm{OH} \\
6 \mathrm{Mn}\left(\mathrm{NH}_{3}\right)_{4}{ }^{2+} & \rightleftarrows 6 \mathrm{Mn}^{2+}+24 \mathrm{NH}_{3}+24 \mathrm{H}_{2} \mathrm{O}+9 \mathrm{OH}^{-} \\
& \rightleftarrows 3 \mathrm{Mn}_{2}(\mathrm{OH})_{3}+24 \mathrm{NH}_{4} \mathrm{OH} \\
6 \mathrm{Mn}\left(\mathrm{NH}_{3}\right)_{4}{ }^{2+} & \rightleftarrows 6 \mathrm{Mn}^{2+}+24 \mathrm{NH}_{3}+24 \mathrm{H}_{2} \mathrm{O}+12 \mathrm{OH}^{-} \\
& \rightleftarrows 6 \mathrm{Mn}(\mathrm{OH})_{2}+24 \mathrm{NH}_{4} \mathrm{OH}
\end{aligned}
$$

The hydroxide $(\mathrm{OH})$ species are substituted with oxygen $(\mathrm{O})$ species in the existence of $\mathrm{NaOH}$ to yield manganese oxides such as $\mathrm{Mn}_{3} \mathrm{O}_{4}, \mathrm{Mn}_{2} \mathrm{O}_{3}$, and $\mathrm{MnO}_{2}$, as shown in Eqs. (3)-(5), 
Table 1. ICP results and weight ratios of manganese oxide

\begin{tabular}{cccc}
\hline Concentration of $\mathrm{NaOH}(\mathrm{M})$ & 0.088 & 0.022 & 0 \\
\hline Weight of $\mathrm{Si}\left(\mathrm{mg} \mathrm{kg}^{-1}\right)$ & 162,000 & 220,300 & 154,900 \\
Weight of $\mathrm{Mn}\left(\mathrm{mg} \mathrm{kg}^{-1}\right)$ & 366,000 & 327,200 & 329,100 \\
$\begin{array}{c}\text { Weight ratio of } \\
\text { manganese oxide (\%) }\end{array}$ & 61.0 & 36.1 & 35.8 \\
\hline
\end{tabular}

respectively. Thus, manganese oxide forms in the sequence of $\mathrm{MnO}_{2}, \mathrm{Mn}_{2} \mathrm{O}_{3}$, and $\mathrm{Mn}_{3} \mathrm{O}_{4}$ phases as the concentration of $\mathrm{NaOH}$ increases. The phases of the manganese oxides may be related to the oxidation states of the Mn species. Table 1 shows the ICP results, which can be used to calculate the weight percentage of the manganese oxide. All samples are prepared using the same weight of manganese precursor and $\mathrm{SiO}_{2}$. The oxidation state of the manganese ions increases from +2 to +4 as the content of the precipitation agent increases. The manganese oxide with a relatively high oxidation state has a higher weight percentage because the number of hydroxide ions per manganese ion increases with increasing manganese ion oxidation state.

Figure 1 shows FE-SEM images of the silica-manganese oxides with a core-shell structure. In Figure 1(a), very uniformly distributed spheres with smooth surfaces are observed for the synthesized $\mathrm{SiO}_{2}$ nanoparticles. For the powders

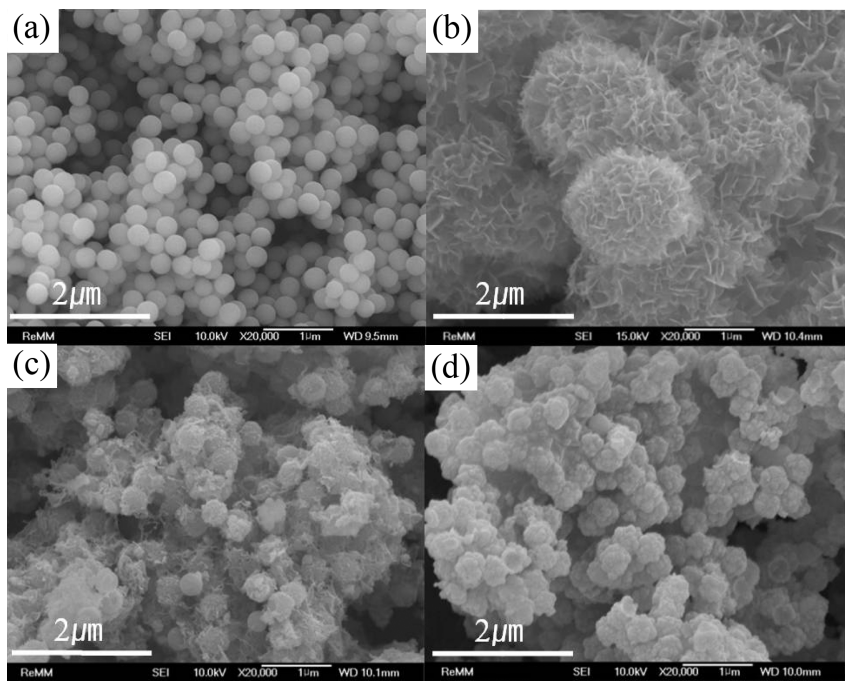

Figure 1. FE-SEM images of (a) pristine silica and silicamanganese oxides after the precipitation reaction at $\mathrm{NaOH}$ concentrations of (b) 0.088 , (c) 0.022 , and (d) $0.000 \mathrm{M}$. obtained through the precipitation reaction (Figs. 1(b)-(d)), the obtained manganese oxides coated onto the surfaces of the $\mathrm{SiO}_{2}$ nanoparticles are very uniform and spherical. In the absence of $\mathrm{NaOH}$ in the precipitation reaction (Fig. 1(b)), a urchin-like morphology is observed, which consists of platelike manganese oxide species on the $\mathrm{SiO}_{2}$ particles, as seen in the high-resolution image shown in Figure 2(a). At low and high concentrations of $\mathrm{NaOH}$, rough surfaces on the $\mathrm{SiO}_{2}$ core are observed with somewhat aggregated porous spherical particles, as seen in Figures 1(c) and 1(d). However, the FE-TEM images in Figures 2(b) and 2(c) confirm a mixture of thin layers and small particles on the surfaces of $\mathrm{SiO}_{2}$ nanoparticles. Both the average diameter and the shell thickness for the powder without $\mathrm{NaOH}$ are higher than those of the other powders. This indicates that the $\mathrm{NaOH}$ precipitating agent plays a role in the distribution and dispersion of the shell species to yield a thin layered coreshell structure.

The XRD patterns of the obtained powders show the accurate chemical species of the shell, as shown in Figure 3. The pristine $\mathrm{SiO}_{2}$ (Fig. 3(a)) shows a weak and broad peak in the range of $20-22.5^{\circ}$, corresponding to its amorphous nature. At a high concentration of $\mathrm{NaOH}$ precipitating agent (Fig. 3(b)), two main peaks ( $\star$ ) corresponding to the (311) and (440) planes of $\mathrm{MnO}_{2}$ appear, which indicate poorly crystalline (space group $\mathrm{I} / \mathrm{m}$ ) $\alpha-\mathrm{MnO}_{2}$ (JCPDS no. 421169). ${ }^{31}$ At a low concentration of $\mathrm{NaOH}$ (Fig. 3(c)), two types of peaks are simultaneously observed: a cubic phase (space group $L a-3$ ) of $\mathrm{Mn}_{2} \mathrm{O}_{3}$ (JCPDS no. 41-1442) (ש) and some planes of a normal tetragonal spinel structure (space group I41/amd) of hausmannite $\mathrm{Mn}_{3} \mathrm{O}_{4}$ (JCPDS no. 1-1127), indicating the coexistence of $\mathrm{Mn}_{3} \mathrm{O}_{4}$ and $\mathrm{Mn}_{2} \mathrm{O}_{3}$ phases. In the absence of $\mathrm{NaOH}$ (Fig. 3(d)), plane peaks ( $)$ of a normal tetragonal spinel structure (space group I41/amd) of hausmannite $\mathrm{Mn}_{3} \mathrm{O}_{4}$ (JCPDS 1-1127) are observed. In addition, it should be noted that all samples contain the same $\mathrm{SiO}_{2}$ peak. Therefore, the shell regions of the obtained powder mainly consist of $\alpha-\mathrm{MnO}_{2}, \mathrm{Mn}_{2} \mathrm{O}_{3}+\mathrm{Mn}_{3} \mathrm{O}_{4}$, and $\mathrm{Mn}_{3} \mathrm{O}_{4}$ as the concentration of $\mathrm{NaOH}$ decreases. Therefore, the core-shell species in the FE-SEM and FE-TEM images are identified as $\mathrm{SiO}_{2}-\mathrm{MnO}_{2}$ (Figs. 1(b) and 2(a)), $\mathrm{SiO}_{2}$ $\mathrm{Mn}_{2} \mathrm{O}_{3}+\mathrm{Mn}_{3} \mathrm{O}_{4}$ (Figs. 1(c) and 2(b)), and $\mathrm{SiO}_{2}-\mathrm{Mn}_{3} \mathrm{O}_{4}$ (Figs. $1(\mathrm{~d})$ and 2(c)) as the concentration of $\mathrm{NaOH}$ decreases.

Figure 4 shows the FT-IR spectra of (a) pristine $\mathrm{SiO}_{2}$ nanoparticles, (b) $\mathrm{SiO}_{2}-\mathrm{MnO}_{2}$, (c) $\mathrm{SiO}_{2}-\mathrm{Mn}_{2} \mathrm{O}_{3}+\mathrm{Mn}_{3} \mathrm{O}_{4}$, and
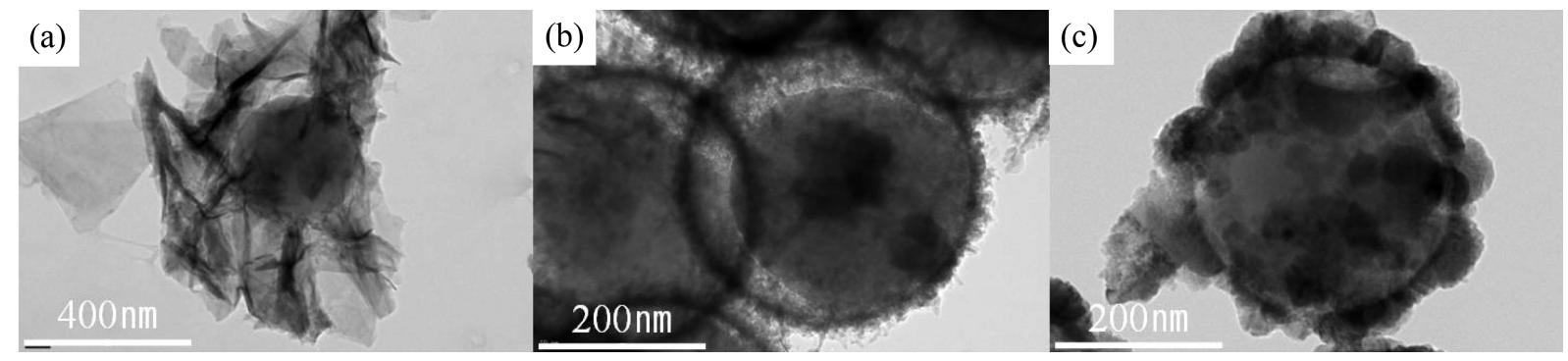

Figure 2. FE-TEM images of silica-manganese oxides after the precipitation reaction at $\mathrm{NaOH}$ concentrations of (a) 0.088 , (b) 0.022 , and (c) $0.000 \mathrm{M}$. 


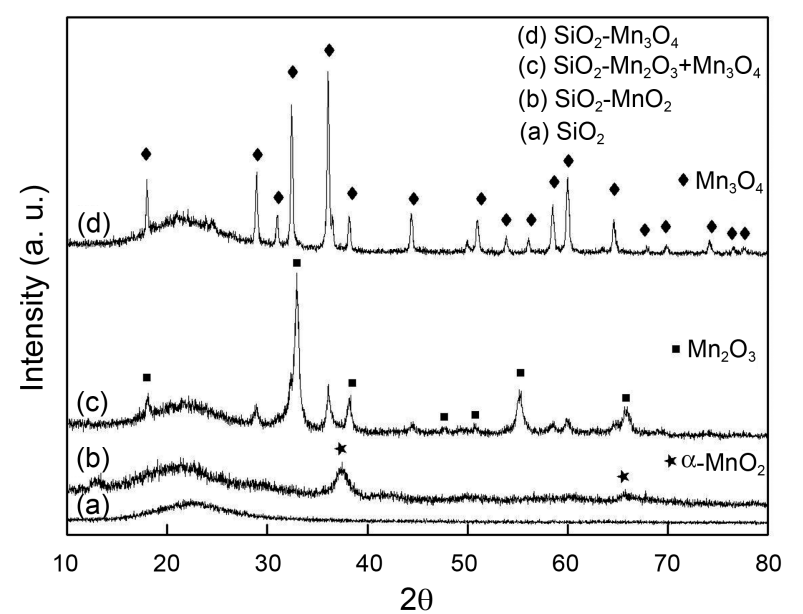

Figure 3. X-ray diffraction pattens of (a) pristine silica and silicamanganese oxides after the precipitation reaction at $\mathrm{NaOH}$ concentrations of (b) 0.088 , (c) 0.022 , and (d) $0.000 \mathrm{M}$. The ( $\star$ ), $(\boldsymbol{\square})$, and $(\bullet)$ symbols correspond to the peaks of $\alpha-\mathrm{MnO}_{2}, \mathrm{Mn}_{2} \mathrm{O}_{3}$, and $\mathrm{Mn}_{3} \mathrm{O}_{4}$, respectively.

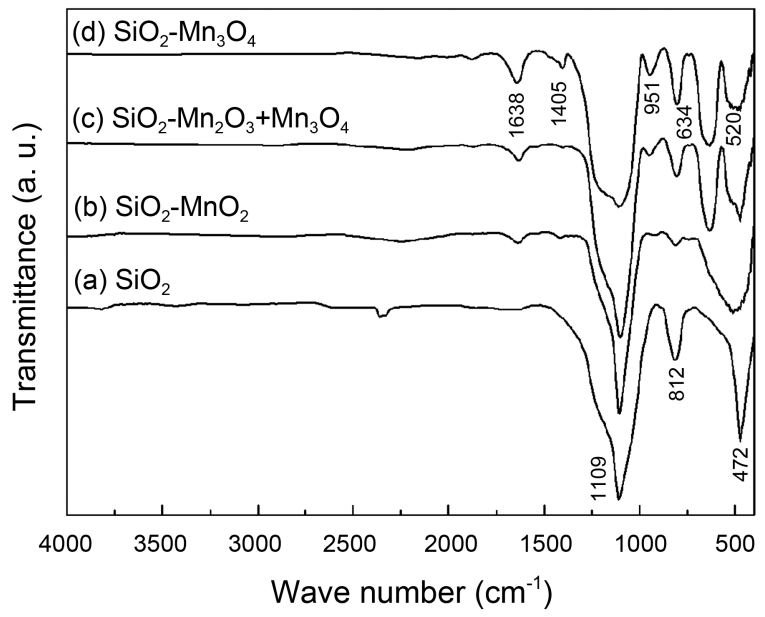

Figure 4. FT-IR spectra of silica-manganese oxides with a coreshell structure: (a) pristine $\mathrm{SiO}_{2}$, (b) $\mathrm{SiO}_{2}-\mathrm{MnO}_{2}$, (c) $\mathrm{SiO}_{2}-$ $\mathrm{Mn}_{2} \mathrm{O}_{3}+\mathrm{Mn}_{3} \mathrm{O}_{4}$, and (d) $\mathrm{SiO}_{2}-\mathrm{Mn}_{3} \mathrm{O}_{4}$.

(d) $\mathrm{SiO}_{2}-\mathrm{Mn}_{3} \mathrm{O}_{4}$ with core-shell structures. All spectra include equal bands related to $\mathrm{SiO}_{2}$ such as the $\mathrm{Si}-\mathrm{O}-\mathrm{Si}$ asymmetric stretching vibration bands at about $1,100 \mathrm{~cm}^{-1}$, the Si-O-Si stretching vibration band at $812 \mathrm{~cm}^{-1}$, and the bending vibration at $472 \mathrm{~cm}^{-1}$. The bands at 1638,1405 , and $1110 \mathrm{~cm}^{-1}$ are normally attributed to $\mathrm{O}-\mathrm{H}$ bending vibrations combined with $\mathrm{Mn}$ atoms, whereas the intense bands observed at 634 and $520 \mathrm{~cm}^{-1}$ are ascribed to the absorption of the Mn-O lattice vibrations in the tetragonally distorted cubic lattice. ${ }^{33}$ These absorption peaks may be associated with the coupling mode between the Mn-O stretching modes of the tetrahedral and octahedral sites. This confirms the formation of the manganese oxide compound.

Combining the characterization results of the silicamanganese oxide powders with a core-shell structure, the formation mechanism shown in Figure 5 is suggested. The surface state of the silica particles after the addition of the

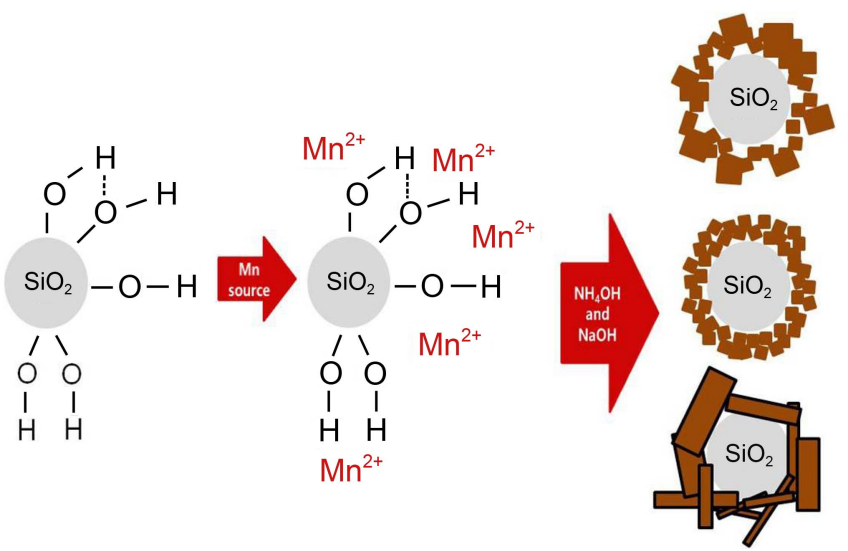

Figure 5. Schematic illustration of the formation mechanism of silica-manganese oxide with a core-shell structure.

Mn source can be ascribed to the dispersion of manganese cations, which yields amine complexes on the silica surfaces after addition of the chelating agent $\left(\mathrm{NH}_{4} \mathrm{OH}\right)$. The thermal treatment in this equilibrium state between the amine complex and the chelating agent involves the aggregated $\mathrm{Mn}_{3} \mathrm{O}_{4}$ phase on the silica surface, according to Eq. (3). Next, the addition of the precipitating agent $(\mathrm{NaOH})$ provides a high concentration of $\mathrm{OH}$ groups, which distributes and disperses the amine complexes to yield thin layer components of $\mathrm{Mn}_{2} \mathrm{O}_{3}$ and $\mathrm{Mn}_{3} \mathrm{O}_{4}$ phases on the silica surface, according to Eqs. (4) and (3), respectively. Further addition of $\mathrm{NaOH}$ results in a thick shell with a urchin-like structure on the silica surface to yield a $\mathrm{MnO}_{2}$ phase, as shown in Eq. (5).

Manganese oxide as a shell component can be used as an active material of supercapacitors. Figure 6 shows the cyclic voltammograms for the silica-manganese oxides with a core-shell structure. The CV curves obtained in a $0.1 \mathrm{M}$ of $\mathrm{Na}_{2} \mathrm{SO}_{4}$ solution at a sweep rate of $5 \mathrm{mV} \mathrm{s}^{-1}$ show a relatively rectangular mirror image with respect to the zero current line, indicating capacitive behavior. The $\mathrm{SiO}_{2}-\mathrm{Mn}_{2} \mathrm{O}_{3}+\mathrm{Mn}_{3} \mathrm{O}_{4}$ and $\mathrm{SiO}_{2}-\mathrm{MnO}_{2}$ show no redox peaks in the range of $-0.2 \mathrm{~V}$

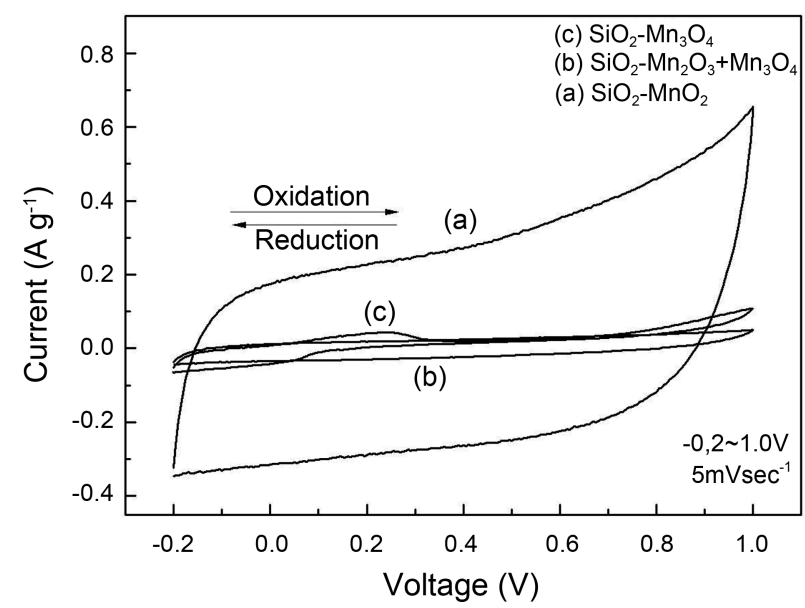

Figure 6. Cyclic voltammograms of silica-manganese oxides with a core-shell structure obtained at a scan rate of $5 \mathrm{mV} \mathrm{s}^{-1}$ : (a) $\mathrm{SiO}_{2}-$ $\mathrm{MnO}_{2}$, (b) $\mathrm{SiO}_{2}-\mathrm{Mn}_{2} \mathrm{O}_{3}+\mathrm{Mn}_{3} \mathrm{O}_{4}$, and (c) $\mathrm{SiO}_{2}-\mathrm{Mn}_{3} \mathrm{O}_{4}$. 


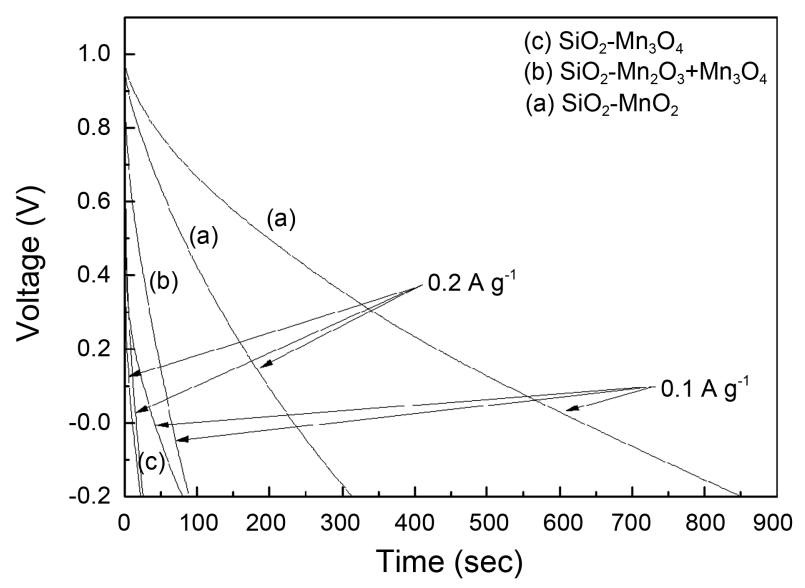

Figure 7. Discharge curves of silica-manganese oxides with a coreshell structure obtained at constant current densities of 0.1 and 0.2 $\mathrm{A} \mathrm{g}^{-1}$ in the potential range of $-0.2 \mathrm{~V}$ to $1.0 \mathrm{~V}$ : (a) $\mathrm{SiO}_{2}-\mathrm{MnO}_{2}$, (b) $\mathrm{SiO}_{2}-\mathrm{Mn}_{2} \mathrm{O}_{3}+\mathrm{Mn}_{3} \mathrm{O}_{4}$, and (c) $\mathrm{SiO}_{2}-\mathrm{Mn}_{3} \mathrm{O}_{4}$.

to $1.0 \mathrm{~V}$, corresponding to ideal capacitive behavior. However, the $\mathrm{SiO}_{2}-\mathrm{Mn}_{3} \mathrm{O}_{4}$ exhibits redox peaks near $0.2 \mathrm{~V}$ and $0.1 \mathrm{~V}$, corresponding to the redox reaction between $\mathrm{Mn}^{2+}$ and $\mathrm{Mn}^{3+}$. The specific capacitance $\left(C_{\mathrm{m}}\right)$ was calculated using the following equation,

$$
C_{\mathrm{m}}=\frac{i}{v},
$$

where $V$ is the potential sweep rate $\left(\mathrm{V} \mathrm{sec}^{-1}\right), i$ is the even current response defined by

$$
i=\left(\int_{V_{\mathrm{a}}}^{V_{\mathrm{c}}} i(v) d V\right) /\left(V_{\mathrm{c}}-V_{\mathrm{a}}\right),
$$

and $V_{\mathrm{a}}$ and $V_{\mathrm{c}}$ represent the lowest and highest voltages, respectively. The value of $i$ is obtained by integrating the area of the $\mathrm{CV}$ curves. The specific capacitance values of $\mathrm{SiO}_{2}-\mathrm{Mn}_{3} \mathrm{O}_{4}, \mathrm{SiO}_{2}-\mathrm{Mn}_{2} \mathrm{O}_{3}+\mathrm{Mn}_{3} \mathrm{O}_{4}$, and $\mathrm{SiO}_{2}-\mathrm{MnO}_{2}$ obtained at a scan rate of $5 \mathrm{mV} \mathrm{s}^{-1}$ are 17,28 , and $197 \mathrm{~F} \mathrm{~g}^{-1}$, respectively. The contribution of $\mathrm{SiO}_{2}$ in the specific capacitance is excluded because $\mathrm{SiO}_{2}$ can be considered as an inactive material of the supercapacitor. The $\mathrm{SiO}_{2}-\mathrm{MnO}_{2}$ case has a higher specific capacitance than does the $\mathrm{MnO}_{2}$ obtained via the hydrothermal method. ${ }^{34}$ The core-shell structure results in non-agglomerated manganese oxide with a narrow size distribution and a spherical shape. Also, the core-shell structure offers many reduction sites for the reduction of manganese oxide.

Figure 7 shows galvanostatic discharge curves obtained between $-0.2 \mathrm{~V}$ to $1.0 \mathrm{~V}$ in a $0.1 \mathrm{M} \mathrm{Na}_{2} \mathrm{SO}_{4}$ solution at current densities of 0.1 and $0.2 \mathrm{~A} \mathrm{~g}^{-1}$. The linear discharge curves indicate good capacitive behavior. The specific capacitance $\left(C_{\mathrm{m}}\right)$ was calculated using the following equation,

$$
C_{\mathrm{m}}=\frac{i t}{\Delta v}
$$

where $i$ is the current density (A), $t$ is time (s), and $\Delta v$ is the potential range $(\mathrm{V})$. The specific capacitance values of $\mathrm{SiO}_{2}$ $\mathrm{Mn}_{3} \mathrm{O}_{4}, \mathrm{SiO}_{2}-\mathrm{Mn}_{2} \mathrm{O}_{3}+\mathrm{Mn}_{3} \mathrm{O}_{4}$, and $\mathrm{SiO}_{2}-\mathrm{MnO}_{2}$ at a current density of $0.1 \mathrm{~A} \mathrm{~g} \mathrm{~g}^{-1}$ are estimated to be 20,22 , and $117 \mathrm{~F} \mathrm{~g}^{-1}$, respectively. The discharge of $\mathrm{SiO}_{2}-\mathrm{Mn}_{3} \mathrm{O}_{4}$ begins at $0.5 \mathrm{~V}$ due to the $i R$ decrease. In the specific capacitance results, the discharge curves are similar to the $\mathrm{CV}$ curves. This may be due to the different oxidation states $(2+, 3+, 4+$, and $6+)$ of manganese oxide. The manganese oxides have electrochemical redox activity because the oxidation state of the manganese can vary from $\mathrm{Mn}^{4+}$ to $\mathrm{Mn}^{3+}$ and from $\mathrm{Mn}^{3+}$ to $\mathrm{Mn}^{2+}$ due to electron transfer. The $\mathrm{Mn}_{2} \mathrm{O}_{3}$ and $\mathrm{Mn}_{3} \mathrm{O}_{4}$ showed poor electronic conductivities. The $\mathrm{MnO}_{2}$ easily participated in redox reactions because it has a higher oxidation state than those of $\mathrm{Mn}_{2} \mathrm{O}_{3}$ and $\mathrm{Mn}_{3} \mathrm{O}_{4}$. Thus, The $\mathrm{SiO}_{2}-$ $\mathrm{MnO}_{2}$ shows higher capacitance values than do $\mathrm{SiO}_{2}-\mathrm{Mn}_{3} \mathrm{O}_{4}$ and $\mathrm{SiO}_{2}-\mathrm{Mn}_{2} \mathrm{O}_{3}+\mathrm{Mn}_{3} \mathrm{O}_{4}$.

\section{Conclusions}

Silica-manganese oxides with core-shell structures were synthesized using a precipitation method. The XRD analysis clarified that the core regions of the composite particles is amorphous $\mathrm{SiO}_{2}$, and the shell region is a combination of poorly crystalline $\alpha-\mathrm{MnO}_{2}$, a cubic phase of $\mathrm{Mn}_{2} \mathrm{O}_{3}$, and a normal tetragonal spinel structure of $\mathrm{Mn}_{3} \mathrm{O}_{4}$. The FT-IR spectra showed that the manganese oxide shell of the $\mathrm{SiO}_{2}$ core gave rise to the presence of new bands at 520, 634, 1109,1405 , and $1638 \mathrm{~cm}^{-1}$ due to the bending vibrations of $\mathrm{O}-\mathrm{H}$, lattice vibrations of the $\mathrm{Mn}-\mathrm{O}$, and the stretching of Mn-O. The FE-SEM and FE-TEM images revealed that shells of $\mathrm{Mn}_{3} \mathrm{O}_{4}, \mathrm{Mn}_{2} \mathrm{O}_{3}$, and $\mathrm{MnO}_{2}$ possess particles, thin layers, and a sea urchin shape with uniform particle sizes of $450 \mathrm{~nm}$ and $1 \mathrm{~mm}$ around the $\mathrm{SiO}_{2}$ core. The synthesized $\mathrm{Mn}_{3} \mathrm{O}_{4}, \mathrm{Mn}_{2} \mathrm{O}_{3}$, and $\alpha-\mathrm{MnO}_{2}$ in the core-shell structure were present at weight percentages of $35.8,36.1$, and $61.0 \%$, respectively. The capacitances of $\mathrm{SiO}_{2}-\mathrm{Mn}_{3} \mathrm{O}_{4}, \mathrm{SiO}_{2}-\mathrm{Mn}_{2} \mathrm{O}_{3}$ $+\mathrm{Mn}_{3} \mathrm{O}_{4}$, and $\mathrm{SiO}_{2}-\mathrm{MnO}_{2}$ were 17, 28, and $197 \mathrm{~F} \mathrm{~g}^{-1}$, respectively. $\mathrm{SiO}_{2}-\mathrm{MnO}_{2}$ demonstrated a higher capacitance than did $\mathrm{SiO}_{2}-\mathrm{Mn}_{3} \mathrm{O}_{4}$ and $\mathrm{SiO}_{2}-\mathrm{Mn}_{2} \mathrm{O}_{3}+\mathrm{Mn}_{3} \mathrm{O}_{4}$.

Acknowledgments. This work was supported by the Midcareer Researcher Program through an NRF grant funded by the MEST (No. 2009-0093818) and by the development program of the local science park funded by the ULSAN Metropolitan City and the MEST (Ministry of Education, Science and Technology).

\section{References}

1. Conway, B. E. Electrochemical Supercapacitor-Scientific Fundamentals and Technological Application; Kluwer Academic: New York, 1999; pp 29-31.

2. Conway, B, E. J. Electrochem. Soc. 1991, 138, 1539.

3. Sarangapani, S.; Tilak, B. V.; Chen, C. P. J. Electrochem. Soc. 1996, 143, 3791 .

4. Burke, A. J. Power Sources 2000, 91, 37.

5. Zheng, J. P.; Jow, T. R. J. Electrochem. Soc. 1995, 142, L6.

6. Zheng, J. P.; Cygan, P. J.; Jow, T. R. J. Electrochem. Soc. 1995, 142, 2699.

7. Devaraj, S.; Munichandraiah, N. J. Electrochem. Soc. 2007, 154, A80. 
8. Lee, H. Y.; Manivannan, A.; Goodenough, J. B. C R Acad Sci. 1999, 200, 565.

9. Lee, H. Y.; Goodenough, J. B. J. Solid State Chem. 1999, 144, 220.

10. Pang, S. C.; Anderson, M. A.; Chapman, T. W. J. Electrochem. Soc. 2000, 147, 444.

11. Pang, S. C.; Anderson, M. A. J. Mater Res. 2000, 15, 2096.

12. Chin, S. F.; Pang, S. C.; Anderson, M. A. J. Electrochem. Soc. 2002, 149, A379.

13. Hu, C. C.; Tsou, T. W. Electrochem. Commun. 2002, 4, 105.

14. Chang, J. K.; Tsai, W. T. J. Electrochem. Soc. 2003, 150, A1333.

15. Ye, C.; Lin, Z. M.; Hui, S. Z. J. Electrochem. Soc. 2005, 152, A1272.

16. Yuan, A.; Zhang, Q. Electrochem. Commun. 2006, 8, 1173.

17. Jeong, Y. U.; Manthiram, A. J. Electrochem. Soc. 2002, 149, A379.

18. Toupin, M.; Brousse, T.; Belange, D. Chem. Mater. 2004, 16, 3184.

19. Prasad, K. R.; Miura, N. J. Power Sources 2004, 135, 354.

20. Liu, E.-H.; Ding, R.; Meng, X.-Y.; Tan, S.-T.; Zhou, J. J. Mater. Sci.: Mater Electron 2007, 18, 1179.

21. Caruso, R. A.; Antonietti, M. Chem. Mater. 2001, 13, 3272.

22. Caruso, F.; Spasova, M.; Salgueirino-Maceira, V.; Liz-Marzán, L.
M. Adv. Mater. 2001, 13, 1090 .

23. Jiang, Z. H.; Liu, C. Y. J. Phys. Chem. B 2003, 107, 12411.

24. Sertchook, H.; Avnir, D. Chem. Mater. 2003, 15, 1690.

25. Mulvaney, P.; Giersig, M.; Ung, T.; Liz-Marzán, L. M. Adv. Mater. $1997,9,570$.

26. Ung, T.; Liz-Marzán, L. M.; Mulvaney, P. Langmuir 1998, 14, 3740 .

27. Oldenburg, S. J.; Averitt, R. D.; Westcott, S. L.; Halas, N. J. Chem. Phys. Lett. 1998, 288, 243.

28. Fleming, M. S.; Mandal, T. K.; Walt, D. R. Chem. Mater. 2001, $13,2210$.

29. Lia, G.; Wanga, Z.; Yua, M.; Quana, Z.; Lin, J. J. Solid State Chem. 2006, 179, 2698.

30. Zou, H.; Wu, S.; Shen, J. Chem. Rev. 2008, 108, 3893.

31. Subramanian, V.; Zhu, H.; Wei, B. Chem. Phys. Lett. 2008, 453, 242.

32. Shinomiya, T.; Gupta, V.; Miura, N. Electrochim. Acta 2006, 51, 4412.

33. Julien, C. M.; Massot, M.; Poinsignon, C. Spectrochim. Acta 2004, 60, 689.

34. Subramanian, V.; Zhu, H.; Wei, B. J. Power Sources 2006, 159, 361. 